\title{
Long-term safety of methotrexate monotherapy in patients with rheumatoid arthritis: a systematic literature research
}

\author{
C Salliot, ${ }^{1}$ D van der Heijde ${ }^{2}$
}

- Additional tables, figure and references are published online only at http://ard.bmi.com/ content/vol68/issue7

${ }^{1}$ Paris Descartes University, Medicine Faculty, Rheumatology B Department, Cochin Hospital, Paris, France; ${ }^{2}$ Rheumatology Department, Leiden University Medical Centre, Leiden, The Netherlands

Correspondence to: Dr C Salliot, Hôpital Cochin, service de Rhumatologie B, rue du faubourg Saint-Jacques, 75014 Paris, France; carinesalliot@gmail.com

Accepted 17 November 2008 Published Online First

5 December 2008

\section{ABSTRACT}

Objective: To perform a systematic literature review of the long-term safety of methotrexate (MTX) monotherapy in rheumatoid arthritis (RA).

Methods: A search was performed in Medline, Cochrane and EMBASE. Adults with RA who had received MTX monotherapy for more than 2 years were studied. Results: 88 published studies were included. Over 12 years of treatment, the termination rate of MTX due to toxicity was less than for sulfasalazine, gold, Dpenicillamine and higher than for hydroxychloroquine (level of evidence 2a-2b). Long-term use of MTX does not appear to be a risk factor for serious infections, including herpes zoster (2b-4), and could provide a survival benefit by reducing cardiovascular mortality (2b). The prevalence of raised liver enzymes (more than twice the upper limit of normal) is close to $13 \%$ of patients; $3.7 \%$ of patients stopped MTX permanently owing to liver toxicity (2b). Data on the risk for liver fibrosis/cirrhosis are conflicting: a meta-analysis showed an incidence of fibrosis of $2.7 \%$ after 4 years of MTX (2a). However, two other studies on sequential liver biopsies did not show evidence for developing severe damage (2b). Insufficient data are available to fully assess the risk of lymphoma and malignancies, although there is no strong evidence of increased risk (2b-4).

Conclusion: This systematic literature search on MTX monotherapy with relatively low-dose use during at least 2 years shows favourable long-term safety.

Rheumatoid arthritis (RA) is a systemic autoimmune disorder characterised by a chronic polyarticular synovial inflammation that may lead to irreversible joint damage with disability and deformity. The conventional treatment of RA combines corticosteroids and disease-modifying antirheumatic drugs (DMARDs), in particular, methotrexate (MTX). In the management of early and established RA, MTX is recommended as a first-line drug by the European League Against Rheumatism (EULAR) and the American College of Rheumatology (ACR). ${ }^{12}$ This drug inhibits the metabolism of folic acid, has a hepatic metabolism and a renal excretion. As an antimetabolic agent, MTX may cause adverse events such as cytopenia, serious infections, liver damage and mucocutaneous problems. Hypersensitivity pneumonitis may also occur during MTX therapy. If MTX is effective, patients usually receive several years of treatment and therefore knowledge about longterm safety is of major importance.

This manuscript is part of the multinational 3E Initiative (Evidence, Expertise, Exchange) to develop recommendations for the management of rheumatic diseases. More background information on this $3 \mathrm{E}$ Initiative and the resulting evidencebased recommendations on the use of MTX are published in this issue of the journal. ${ }^{3}$ This paper describes the literature review to answer the question: "What is the long-term safety of methotrexate, including cardiovascular diseases, malignancies, infections and liver toxicity?".

\section{METHODS}

\section{Systematic literature search}

To summarise the published evidence for the long-term safety of MTX in patients with RA a systematic literature search was performed. The process of the search, described step by step is provided as supplemental material on the website (http://www.annrheumdis.com/supplemental, table $1 \mathrm{w})$. The most important decisions were to define long term as more than 2 years, to focus on patients with RA, treated with MTX as monotherapy.

Thereafter, we selected the relevant key words in Medline with the help of a librarian, defining the exact population, intervention and control groups as well as the outcomes. Several combinations of key-words (supplemental table $2 \mathrm{w}$, online only) were used to search in Medline, EMBASE and Cochrane Central (without limitation in time, journal or languages). We completed this search with the ACR and EULAR abstracts of the past 3 years (2005-7). The search was performed on studies published until October 2007. Using predefined inclusion and exclusion criteria, we screened all the references obtained in the three databases. The selection was initially made using the titles and the abstracts, then for the remaining studies by reading the complete paper. This search in each database and the screening was performed twice by the same person (CS).

The next step was the assessment of the level of evidence of each of the included studies, using the evidence-based medicine levels of evidence (Oxford, May 2001, http://www.cebm.net (accessed 21 April 2008). This five-level scale classifies the level of evidence according to the study design with 1 as the highest level of evidence (supplemental table 1w, online only).

\section{Data extraction and analysis}

For each included study, the study design, quality using the Oxford scale, number of included patients, definition of comparator groups, duration of use and mean dose of MTX, duration of follow-up as online under the BMJ Journals unlocked scheme, see http:// ard.bmj.com/info/unlocked.dtl 
well as the results expressed in incidence rates, risk (relative risk (RR) or odds ratio), incidence rate (IR) or standardised mortality rate have been described. When appropriate, we also pooled the results of the prospective cohort studies for each type of adverse event. The pooled results provided in this review are expressed as percentages of patients experiencing a particular adverse event and have been calculated as (number of new adverse events/ number of patients at risk during the follow-up) $\times 100$. The data were not sufficiently detailed to be able to calculate the events per patient per year of follow-up.

\section{RESULTS}

\section{Results of the literature search}

We obtained 2574 abstracts. Based on titles and abstracts and, for some of the papers, by reviewing the full paper, we excluded 2490 published studies consistent with our predefined inclusion and exclusion criteria. The details of the selection process and the reasons for exclusion appear for each database in the flow chart (fig 1, online only).

Finally, 88 published studies and three congress abstracts (all references are listed in the online supplemental data available at http://www.annrheumdis.com/supplemental) were included for the analysis. They contain data on mortality, general toxicity, infections, cardiovascular diseases, liver toxicity, malignancies, cytopenia and pulmonary involvement. No randomised controlled trial could be included because of the $<2$ years' duration of MTX treatment in randomised controlled trials. Table $3 \mathrm{w}$ (online only) provides the number of studies for each topic in detail, grouped according to the study design. We included two meta-analyses, 54 prospective studies and three case-control studies in our review.

\section{Toxicity in general}

\section{Termination rates for toxicity}

During up to 12.7 years of treatment, the rates of discontinuation for toxicity in the MTX groups presented as the range of the various studies (10-37\%) were less than for sulfasalazine treatment (17-52\%), D-penicillamine (24-55\%) and gold (22$64 \%)$ treatments, but higher than for hydroxychloroquine (HCO) (10-14\%) (table 4w, online only).

\section{Adverse events}

To examine the adverse events in patients receiving MTX, we retained and pooled the results from the 21 prospective studies presenting the number of adverse events (table 1). ${ }^{4-24}$ Thus, among 3463 patients with RA who received on average a low dose of MTX ( $8.8 \mathrm{mg} /$ week) for a mean duration of 36.5 months, $72.9 \%$ of patients had at least one adverse event.
The most common adverse events were gastrointestinal and elevation of liver enzymes.

Kremer et al performed a long observational study (up to 104 months, mean doses of MTX between 12.4 and $14.6 \mathrm{mg} /$ week) in a small number of patients (level of evidence $2 b$ ). ${ }^{21-23}{ }^{25}$ At baseline, 29 patients were included and after 79 months, 20 remained in the study. The prevalence of patients who experienced side effects after 2 years of treatment was 79-85\% and constant over time (up to 104 months). Gastrointestinal adverse events were the most common side effect (52-65\%) and had similar incidence whatever the duration of MTX. Elevations of liver enzymes (above the upper limit of normal) occurred especially during the first 4 years of treatment (69-88\%) and then decreased ( $25 \%$ then $15 \%$ after 79 months). The number of neurological events (headache, light headedness, fatigue, vertigo, feeling "out of sorts", 21-38\%) and leukopenia (20-25\%) also remained constant over time. Four withdrawals occurred before 53 months of treatment.

Using the ARAMIS data bank (Arthritis Rheumatism and Aging Medical Information System), Fries et al compared the toxicity of commonly used DMARDs in RA (level 2b). ${ }^{26}$ They used a toxicity index computed from clinical symptoms, laboratory abnormalities and hospitalisations reported by patients, health professionals and doctors. ${ }^{27}$ According to this score, HCQ was statistically less toxic than all other DMARDs, while auranofin was the most toxic. HCO was followed by intramuscular gold and as one group closely together D-penicillamine, MTX and azathioprine. This toxicity score is not usually routinely used probably because of it complexity.

\section{Methotrexate pneumonitis}

According to the results from the 21 prospective studies, only 15 cases of MTX pneumonitis occurred among the 3463 patients with RA receiving MTX $(0.43 \%)$ up to 36.5 months (table 1$)$. MTX pneumonitis, considered as an acute hypersensitivity reaction, occurs early in the course of MTX, thus it does not seem to be a problem of long-term treatment by MTX.

\section{Cytopenia relative to long-term MTX treatment}

Table 1 also shows data on cytopenia: 179 events of cytopenia in one cell line $(5.2 \%)$ occurred in patients with RA receiving MTX up to 36.5 months. The rate of thrombopenia was $4.1 \%$ in a retrospective study. ${ }^{28}$ Pancytopenia seems to be less common with an incidence of $0.96-1.4 \%$ in a few retrospective studies (level 4). ${ }^{29}$

\section{Mortality in patients with RA who received long-term MTX}

Table $5 \mathrm{w}$ (online only) gives details of the active cohort. The mortality IR of the MTX group (23 per 1000 person-years) was

Table 1 Most common adverse events (AEs) attributed to methotrexate (MTX) and permanent discontinuation due to toxicity in patients with rheumatoid arthritis (RA): pooled results from 21 prospective cohorts (level of evidence $2 b)^{4-24}$

\begin{tabular}{lllllllllllll}
\hline & & $\begin{array}{l}\text { Mean dose of } \\
\text { MTX } \\
\text { (mg/week) }\end{array}$ & $\begin{array}{l}\text { Mean } \\
\text { duration of } \\
\text { MTX } \\
\text { (months) }\end{array}$ & $\begin{array}{l}\text { Number of } \\
\text { all AEs }\end{array}$ & $\begin{array}{l}\text { Permanent } \\
\text { discontinuation }\end{array}$ & $\begin{array}{l}\text { Gastro- } \\
\text { intestinal }\end{array}$ & Liver & Skin/hair & $\begin{array}{l}\text { Central } \\
\text { nervous } \\
\text { system }\end{array}$ & \multicolumn{1}{c}{ Cytopenia } & Lung \\
\hline Number & Patients & 3463 & 8.8 & 36.5 & 2524 & $315 / 3007^{*}$ & 1065 & 640 & 309 & 191 & 179 & $84(15 \dagger)$ \\
Range & $24-1155$ & $4.6-18$ & $27-132$ & $22-475$ & & $10-257$ & $0-122$ & $0-111$ & $0-58$ & $0-27$ & $0-28$ \\
$\%$ & & & & 72.9 & 10.5 & 30.8 & 18.5 & 8.9 & 5.5 & 5.2 & $2.4(0.43) \dagger$
\end{tabular}

*Total number of patients in studies with data available concerning permanent discontinuation of MTX

Gastrointestinal (Gl): stomatitis, ulcer, abdominal pain, GI bleed, dyspepsia, nausea, vomiting, diarrhoea, weigh loss, appetite loss; liver toxicity: increase of aspartate aminotransferase and/or alanine aminotransferase upper limit of normal; skin/hair: ulcer, pruritis, skin rash, alopecia, skin itching, moon face, eczema; central nervous system: headache, depression, blurred vision, transient ischemic attack, stroke, vertigo, lethargy, malaise, fatigue; cytopenia: haemoglobin decreased $>2$ gm/dl or platelets $<150000 / \mathrm{mm}^{3}$, white blood cells $<3500 / \mathrm{mm}^{3}$; lung: MTX pneumonitis $(\dagger)$, pulmonary dysfunction, cough and unspecified pulmonary adverse drug reactions. 
Table 2 Elevation of liver enzymes during methotrexate (MTX) treatment: pooled results of 27 prospective studies $^{4-24}{ }^{35-40}$ (level 2b)

\begin{tabular}{llllll}
\hline $\begin{array}{l}\text { Number of } \\
\text { patients }\end{array}$ & $\begin{array}{l}\text { Mean dose of } \\
\text { MTX (mg/week) }\end{array}$ & $\begin{array}{l}\text { Mean duration } \\
\text { (months) }\end{array}$ & $\begin{array}{l}\text { Abnormally high } \\
\text { ALT or AST }\end{array}$ & $\begin{array}{l}\text { ALT or AST } \\
>2 \text { ULN }\end{array}$ & $\begin{array}{l}\text { Permanent } \\
\text { discontinuation }\end{array}$ \\
\hline $3808(16-1155)$ & $10.5(4.6-18)$ & $55.8(27-180)$ & $769(20.2 \%)$ & $114 / 883^{*}(12.9 \%)$ & $66 / 1799^{*}(3.7 \%)$ \\
\hline
\end{tabular}

Results are shown as number (\%) or number (range).

*Total number of patients in studies with data available concerning permanent discontinuation of MTX.

ALT, alanine aminotransferase; AST, aspartate aminotransferase; ULN, upper limit of normal.

in line with the IR in the group not receiving MTX (26.7 per 1000 person-years). Moreover, MTX may provide a survival benefit by reducing cardiovascular mortality in comparison with patients with RA treated with other DMARDs (adjusted hazard ratio of cardiovascular mortality 0.3 (95\% CI 0.2 to 0.7 ). However, in the retrospective cohort the RR for mortality was 3.4 in patients with RA with a history of cardiovascular diseases (CVD) starting MTX as compared with patients with RA without CVD who started MTX and patients who started other DMARDs and patients with CVD but not receiving MTX.

Risk of CVDs in patients with RA who received long-term MTX Two case-control studies were included to estimate the risk of CVD during MTX treatment (table 5w, online only). One study concluded that MTX is not a risk factor for CVD in patients with RA and the second study even found a reduced risk compared with patients with RA who never received MTX, sulfasalazine or $\mathrm{HCQ}$.

\section{Infections in patients with RA receiving long-term of MTX}

Table $5 \mathrm{w}$ (online only) summarises six studies included in the analyses. Over 3 years of treatment, $8.3 \%$ of patients had serious infections, and a large majority of infections (79\%) occurred during the first 2 years of treatment. According to the studies included, MTX does not seem to be associated with a higher risk for infections, in general, or serious infections, including herpes zoster and infectious complications, after total hip or knee replacements.

\section{Lymphoma and malignancies}

Overall, patients with RA have an increased risk of lymphoma in comparison with the general population, which is mainly related to high levels of disease activity. ${ }^{30}$ A relationship between MTX treatment and the occurrence of lymphoproliferative disorders (LPDs) in RA has been topic of discussion for many years. MTX could be associated with Epstein-Barr virus-related LPD and patients with spontaneous regressions of LPD after MTX withdrawal have been described. ${ }^{31}$

The studies included in this review did not allow us to assess fully the risk of long-term MTX treatment on the occurrence of lymphoma and malignancies in patients with RA, although there does not seem to be an indication of an increased risk (table $5 \mathrm{w}$, online only).

For the risk of lymphoma, most of the studies compared MTX groups with the general population and not with patients with RA who did not receive MTX. Wolfe's study is the only study providing the incidence rates of lymphoma in patients with RA with and without MTX. In the MTX group, this rate is higher than in the "no MTX, no biological agent" group. Unfortunately, no adjustment on RA severity was performed. Thus this higher incidence might be due to a higher severity of RA in the MTX group and not to the drug effect itself. For other malignancies, there are no data on the risk of MTX use in comparison with patients with RA who have received other DMARDs as a control group.

Liver toxicity in patients with RA who received long-term MTX Elevation of liver enzymes is the second most common adverse event during MTX treatment after gastrointestinal side effects (table 2). To evaluate the incidence of elevation of liver enzymes, we pooled the results from 27 prospective studies that evaluated a total of 3808 patients with RA who received a low dose of MTX (10.5 mg/week) during 55.8 months, on average..$^{4-24}$ 32-37 A total of 769 patients had at least one episode of elevated liver enzymes (20.2\%), $12.9 \%$ had an elevation up to two times the upper limit of normal and $3.7 \%$ of patients stopped MTX because of liver toxicity.

\section{Liver damage evaluated on liver biopsy}

One meta-analysis (table $6 \mathrm{w}$, online only) provides the results of sequential liver biopsies performed systematically in patients receiving MTX. These results have to be judged with caution because these studies were all uncontrolled and some do not report baseline biopsy results. The meta-analysis suggests that $3 \%$ of patients would develop severe fibrosis or cirrhosis over 55 months' treatment with MTX, especially if they drink at least $100 \mathrm{~g}$ of alcohol a week (corresponding to 10 glasses a week).

In the two studies with baseline biopsies, not a single patient had evidence of severe fibrosis or cirrhosis after 4 years of treatment (cumulative dose of MTX around $2000 \mathrm{mg}$ ). ${ }^{21} 38$

\section{DISCUSSION}

To date, this is the first review that specifically deals with the long-term safety of MTX monotherapy in patients with RA. According to the cohort and case-control studies, there is no evidence of an increased risk of CVD, mortality and infections in patients receiving MTX. Overall, although many patients experience adverse events during MTX treatment, they are generally mild and withdrawals of MTX for toxicity are less common than for most other DMARDs. The results remain inconclusive for the risk of cirrhosis and malignancies, including lymphoma.

There are challenges to the interpretation of the data as several weaknesses were apparent in the results of the systematic literature search. First, the studies were heterogeneous in their study design, the level of evidence, the type of adverse events reported, the presentation of the results as prevalence, incidence rate, RR, etc. Moreover, the control groups were not always well defined and described. Also, information on relevant data such as comorbidity, concomitant use of other drugs and folic acid supplementation were often not available. Consequently, we could only pool the results for the adverse events in general and elevation of liver enzymes from uncontrolled prospective studies. But even here, we were unable to present the occurrence of adverse events per patient per year of exposure. 
Second, the focus of the systematic literature search is on use of MTX as monotherapy. This is valid but does limit the interpretation on the long-term safety of MTX in combination with other DMARDs and/or biological agents which is often the case in modern treatment of RA.

Third, the average dose of $10.7 \mathrm{mg} /$ week overall in all studies, with a maximum dose of $18 \mathrm{mg} /$ week in one study, is low compared with the currently recommended dose. We tried to evaluate a time trend in the dosage of MTX use but the mean dose in the studies published before 1995 was similar to the dose used in the studies published after 1995. Recent publications do include data on the use of MTX in higher dosages, but there is only information on long-term safety in one of these studies. ${ }^{39}$ However, this study shows no difference in frequency and type of adverse events from those in the studies with lower dosages. But in general, the data provided in this systematic literature search relate to the long-term safety of relatively low doses of MTX.

Fourth, nowadays concomitant use of folic acid and MTX is standard treatment. Most of the studies did not report or insufficiently reported the use of folic acid. Therefore, we do not know what the role of folic acid is in the long-term safety of MTX. However, within the 3E Initiative there is a specific systematic literature search on the usefulness of adding folic acid to MTX. ${ }^{40}$

Although the data on cirrhosis and malignancies are inconclusive, the findings of this review do not suggest serious problems of toxicity with the long-term use of MTX as monotherapy with an average dose of $10.7 \mathrm{mg} /$ week in patients with RA. Many patients experience adverse events, but these are usually of mild. Whether these conclusions are valid for higher doses and in combination with other DMARDs and biological agents needs to be investigated by future research. The data from this systematic literature search were used as one of the evidence-based pieces of information forming the basis for the recommendations on the use of MTX in rheumatic diseases. ${ }^{3}$

Acknowledgements: We thank Professor Maxime Dougados, Professor Loreto Carmona, Professor Claire Bombardier, Dr Wanda Katchamart, Dr Karen Visser, Dr Estebaliz Loza, Dr Juan-Antonio Martinez, Dr Judith Trudeau and the 3E scientific committee for their help, suggestions and support.

Funding: This work was supported by Abbott with an unrestricted educational grant.

Competing interests: None.

\section{REFERENCES}

1. Combe B, Landewe R, Lukas C, Bolosiu HD, Breedveld F, Dougados M, et al. EULAR recommendations for the management of early arthritis: report of a task force of the European Standing Committee for International Clinical Studies Including Therapeutics (ESCISIT). Ann Rheum Dis 2007;66:34-45.

2. Saag KG, Teng GG, Patkar NM, Anuntiyo J, Finney C, Curtis JR, et al. American College of Rheumatology. American College of Rheumatology 2008 recommendations for the use of non biologic and biologic disease-modifying antirheumatic drugs in rheumatoid arthritis. Arthritis Rheum 2008;59:762-84.

3. Visser K, Katchamart W, Loza E, Martinez-Lopez JA, Salliot C, Trudeau J, et al. Multinational evidence-based recommendations for the use of methotrexate in rheumatic disorders: integrating systematic literature research and expert opinion of a broad international panel of rheumatologists in the $3 E$ Initiative. Ann Rheum Dis 2009:68:1086-93.

4. Weinblatt ME, Weissman BN, Holdsworth DE, Fraser PA, Maier AL, Falchuk KR, et al. Long-term prospective study of methotrexate in the treatment of rheumatoid arthritis. 84-Month update. Arthritis Rheum 1992;35:129-37.

5. McKendry RJ, Cyr M. Toxicity of methotrexate compared with azathioprine in the treatment of rheumatoid arthritis. Arch Intern Med 1989;149:685-9.

6. Weinstein A, Marlowe S, Korn J, Farouhar F. Low-dose methotrexate treatment of rheumatoid arthritis. Long-term observations. Am J Med 1985; 19:331-7.

7. Furst DE, Erikson N, Clute L, Koehnke R, Burmeister LF, Kohler JA. Adverse experience with methotrexate during 176 weeks of a longterm prospective trial in patients with rheumatoid arthritis. J Rheumatol 1990;17:1628-35.
8. Alarcon GS, Tracy IC, Blackburn WD Jr. Methotrexate in rheumatoid arthritis. Toxic effects as the major factor in limiting long-term treatment. Arthritis Rheum 1989;32:671-6.

9. Yamanaka H, Inoue E, Tanaka E, Nakajima A, Taniguchi A, Terai C, et al. Influence of methotrexate dose on its efficacy and safety in rheumatoid arthritis patients: evidence based on the variety of prescribing approaches among practicing Japanese rheumatologists in a single institute-based large observational cohort (IORRA). Mod Rheumatol 2007;17:98-105.

10. Weinblatt ME, Maier AL, Fraser PA, Coblyn JS. Longterm prospective study of methotrexate in rheumatoid arthritis: conclusion after 132 months of therapy. J Rheumatol 1998;25:238-42.

11. Rau R, Schleusser B, Herborn G, Karger T. Long-term treatment of destructive rheumatoid arthritis with methotrexate. J Rheumatol 1997:24:1881-9.

12. Schnabel A, Herlyn K, Burchardi C, Reinhold-Keller E, Gross WL. Long-term tolerability of methotrexate at doses exceeding $15 \mathrm{mg}$ per week in rheumatoid arthritis. Rheumatol Int 1996;15:195-200.

13. Salaffi F, Carotti M, Sartini A, Cervini C. A prospective study of the long-term efficacy and toxicity of low-dose methotrexate in rheumatoid arthritis. Clin Exp Rheumatol 1995;13:23-8.

14. Szanto E. Low-dose methotrexate treatment of rheumatoid arthritis; long-term observation of efficacy and safety. Clin Rheumatol 1989:8:323-20.

15. Hanrahan PS, Scrivens GA, Russell AS. Prospective long term follow-up of methotrexate therapy in rheumatoid arthritis: toxicity, efficacy and radiological progression. Br J Rheumatol 1989;28:147-53.

16. Weinblatt ME, Trentham DE, Fraser PA, Holdsworth DE, Falchuk KR, Weissman BN et al. Long-term prospective trial of low-dose methotrexate in rheumatoid arthritis. Arthritis Rheum 1988;31:167-75.

17. Tishler M, Caspi D, Yaron M. Long-term experience with low dose methotrexate in rheumatoid arthritis. Rheumatol Int 1993;13:103-6.

18. Sander 0, Herborn G, Bock E, Rau R. Prospective six year follow up of patients withdrawn from a randomised study comparing parenteral gold salt and methotrexate. Ann Rheum Dis 1999;58:281-7.

19. Menninger H, Herborn G, Sander O, Blechschmidt J, Rau R. A 36 month comparative trial of methotrexate and gold sodium thiomalate in the treatment of early active and erosive rheumatoid arthritis. Br J Rheumatol 1998;37:1060-8.

20. Nagashima N, Matsuoka T, Saitoh K, Koyama T, Kikuchi O, Yoshino S. Treatment continuation rate in relation to efficacy and toxicity in long-term therapy with lowdose methotrexate, sulfasalazine, and bucillamine in 1358 Japanese patients with rheumatoid arthritis. Clin Exp Rheumatol 2006;24:260-7.

21. Kremer JM, Lee JK. The safety and efficacy of the use of methotrexate in long-term therapy for rheumatoid arthritis. Arthritis Rheum 1986;29:822-31.

22. Kremer JM, Lee JK. A long-term prospective study of the use of methotrexate in rheumatoid arthritis. Update after a mean of fifty-three months. Arthritis Rheum 1988; 31:577-84.

23. Kremer JM, Phelps CT. Long-term prospective study of the use of methotrexate in the treatment of rheumatoid arthritis. Update after a mean of 90 months. Arthritis Rheum 1992:35:138-45.

24. Tilling L, Townsend S, David J. Methotrexate and hepatic toxicity in rheumatoid arthritis and psoriatic arthritis. Clin Drug Investig 2006;26:55-62.

25. Kremer JM. Safety, efficacy, and mortality in a long-term cohort of patients with rheumatoid arthritis taking methotrexate: followup after a mean of 13.3 years. Arthritis Rheum 1997; 40:984-5

26. Fries JF, Williams CA, Ramey D, Bloch DA. The relative toxicity of disease-modifying antirheumatic drugs. Arthritis Rheum 1993;36:297-306.

27. Fries JF, Spitz PW, Williams CA, Bloch DA, Singh G, Hubert HB. A toxicity index for comparison of side effects among different drugs. Arthritis Rheum 1990;33:121-30.

28. Franck $\mathbf{H}$, Rau R, Herborn $G$. Thrombocytopenia in patients with rheumatoid arthritis on long-term treatment with low dose methotrexate. Clin Rheumatol 1996;15:163-7.

29. Gutierrez-Urena S, Molina JF, Garcia CO, Cuellar ML, Espinoza LR. Pancytopenia secondary to methotrexate therapy in rheumatoid arthritis. Arthritis Rheum 1996; 39:272-6.

30. Baecklund E, Ekbom A, Sparén P, Feltelius N, Klareskog L. Disease activity and risk of lymphoma in patients with rheumatoid arthritis: nested case-control study. BMJ 1998:317:180-1.

31. Kamel OW, van de Rijn M, LeBrun DP, Weiss LM, Warnke RA, Dorfman RF. Lymphoid neoplasms in patients with rheumatoid arthritis and dermatomyositis: frequency of Epstein-Barr virus and other features associated with immunosuppression. Hum Pathol 1994;25:638-43.

32. Beyeler C, Reichen J, Thomann SR, Lauterburg BH, Gerber NJ. Quantitative liver function in patients with rheumatoid arthritis treated with low-dose methotrexate: a longitudinal study. Br J Rheumatol 1997;36:338-44.

33. Ros S, Juanola X, Condom E, Canas C, Riera J, Guardiola J, et al. Light and electron microscopic analysis of liver biopsy samples from rheumatoid arthritis patients receiving long-term methotrexate therapy. Scand J Rheumatol 2002;31:330-6.

34. Fathi NH, Mitros F, Hoffman J, Straniero N, Labreque D, Koehnke R, et al. Longitudinal measurement of methotrexate liver concentrations does not correlate with liver damage, clinical efficacy, or toxicity during a 3.5 year double blind study in rheumatoid arthritis. J Rheumatol 2002;29:2092-8.

35. Willkens RF, Leonard PA, Clegg DO, Tolman KG, Ward JR, Marks CR, et al. Liver histology in patients receiving low dose pulse methotrexate for the treatment of rheumatoid arthritis. Ann Rheum Dis 1990;49:591-3.

36. Hoffmeister RT. Methotrexate therapy in rheumatoid arthritis: 15 years experience. Am J Med 1983;75:69-73. 
37. Arias JM, Morton KA, Albro JE, Patch GG, Valdivia S, Greenberg HE, et al.

Comparison of methods for identifying early methotrexate-induced hepatotoxicity in patients with rheumatoid arthritis. J Nucl Med 1993;34:1905-9.

38. Tishler M, Caspi D, Halperin Z, Baratz M, Moshkowitz M, Yaron M. A prospective analysis of liver biopsies in rheumatoid arthritis patients receiving long term methotrexate therapy. Rheumatol Int 1992;12:39-41.
39. van der Heijde D, Klareskog L, Landewé R, Bruyn GA, Cantagrel A, Durez P, et al. Disease remission and sustained halting of radiographic progression with combination etanercept and methotrexate in patients with rheumatoid arthritis. Arthritis Rheum 2007;56:3928-39.

40. Katchamart W, Ortiz Z, Shea B, Tugwell P, Bombardier C. Folic acid and folinic acid for reducing side effects in patients receiving methotrexate for rheumatoid arthritis (an update systematic review and meta-analysis) EULAR 2008: abstr THU0186. 